Brazilian Journal

of Chemical

ISSN 0104-6632

Engineering

\title{
INVESTIGATION OF PAPER DRYER PICKING, WEB TRANSFER AND QUALITY ISSUES USING A NEW WEB ADHESION AND DRYING SIMULATOR
}

\author{
F. Ahrens*, T. Patterson, S. Mueller and B. Hojjatie \\ Georgia Institute of Technology, Institute of Paper Science and Technology, \\ Phone: +(55) (404) 894-6496, Fax: +(55) (404894-4778, \\ $50010^{\text {th }}$ Street, N.W., Atlanta, Georgia, 30332-0620, USA \\ E-mail: fred.ahrens@ipst.gatech.edu
}

(Received: October 20, 2004 ; Accepted: November 20, 2004)

\begin{abstract}
Paper dryer surface contamination can influence the severity of fiber picking, result in increased adhesion of the paper web to the surface, and impact the severity of cockle (out-of-plane deformation), a paper quality issue. The Web Adhesion and Drying Simulator (WADS) is a unique apparatus designed for investigation of paper sticking and fiber picking. Using the WADS, it has been found that the work of separation and amount of picking depend on roll surface material, contamination and temperature, and on the composition, moisture content and temperature of the web, and contact time. The WADS was also found to be convenient for studying the effect of drying conditions on severity of cockle. Cockle was found to depend on ingoing sheet solids content, surface temperature and degree of heat transfer non-uniformity.

Keywords: Paper drying; Drying simulator; Adhesion; Fiber picking; Cockle.
\end{abstract}

\section{INTRODUCTION}

Dryer cylinder contamination can create significant operating problems for the papermaker. The contamination generally has "sticky" components that can influence the severity of fiber picking and result in increased adhesion of the paper web to the dryer surface. In addition to potentially causing a detrimental effect on paper quality, contamination and resulting adhesion can affect the machine productivity due to increased web breaks (higher sheet tension) and downtime for cleaning the dryer cylinders. Typically, the first dryer section is also run with temperature graduation, in an effort to decrease the rate of contaminant buildup, further reducing potential machine productivity. As the contaminants accumulate on the dryer surface, the heat transfer rate and uniformity from the dryer cylinder to the sheet are decreased, as well. Furthermore, the non-uniform heat transfer may impact the occurrence and severity of sheet cockle.

The interaction between two competing factors, web adhesion to the surface and web cohesion, has been shown [Shallhorn and Karnis, 1975] to influence the degree of picking under wet pressing conditions. For the dryer surface, as well, it would be expected that, when adhesive forces exceed the cohesive strength of the web, picking will increase and the work required to separate the web from the cylinder surface will also change. By recognizing the factors that cause and foster the picking and sticking phenomena, optimum dryer operating strategies for managing their impact can be determined.

Meinecke, et al. [1988] conducted a study with a pilot dryer cylinder, and related picking to ingoing

*To whom correspondence should be addressed 
solids, surface temperature and machine speed (contact time). This was a qualitative study; the corresponding work of adhesion/separation was not measured. These authors pointed out that, in order to resolve a picking problem resulting from a given drying condition, a large increase or decrease in dryer temperature is necessary. These authors postulated that this primary dependence on temperature is due to the change in softening point of lignin and hemicelluloses with water content. Picking occurs when the temperature of the sheet exceeds the softening point, which can be lowered by the presence of water.

Much of the pioneering work to quantify adhesion phenomena (in relation to wet pressing) was done by Mardon [1976, 1961]. He built a low speed laboratory peel tester ("sheet stripper") to measure the peel force (tension) and relate it to peel angle and speed. Mardon developed an equation relating the peel force to the work of adhesion (or separation):

$\mathrm{T}^{\prime}=\frac{\mathrm{W}^{\prime \prime}}{1-\cos \phi}+\mathrm{mV}_{1}^{2}$

where $\mathrm{T}^{\prime}=$ tension per unit width, W" $=$ work of adhesion (or separation) per unit area, $\mathrm{m}=$ mass per unit area, $V_{1}=$ velocity of the sheet, and $\phi=$ peel angle (relative to the surface tangent at the peel point).

Work of adhesion (or separation) is a fundamental parameter that may depend on a number of factors including surface topology, surface materials, surface energy, contaminants, fiber characteristics, application pressure, surface and sheet temperature, and sheet moisture content.

The laboratory devices developed and used by previous researchers [Mardon, 1961, 1976; Shallhorn and Karnis, 1975] interested in adhesion were limited to room temperature operation (more applicable to press roll applications). For a comprehensive investigation of dryer cylinder picking and sticking it is essential to provide surface and initial web temperatures representative of those in the dryer section. Furthermore, it is essential to provide for contact between the web and surface over controlled time intervals representative of those for which the sheet touches a dryer cylinder at typical machine speeds. The conditions at the sheetroll surface interface during drying are highly time- dependent, and they are expected to have a strong influence on adhesion and picking. The Web Adhesion and Drying Simulator (WADS) was thus designed and constructed to support experimental measurement of web separation (peeling tension) under controlled conditions simulating various dryer operating conditions.

A detailed, descriptive theory of how nonuniformity in shrinkage and dried-in strains cause cockle (out-of-plane deformation) is given in Smith [1950]. He also discussed some of the factors in the papermaking process that could contribute to cockle development, such as basis weight variation, moisture variation, fiber orientation variation and low drying restraint. Ueska [1991] later gave a more concise description of Smith's proposed mechanism of cockle generation. Brecht, et al. [1955] have performed thorough experiments to test and demonstrate Smith's theory of cockle. They investigated the influence of initial moisture nonuniformity and heating non-uniformity, and several other variables, on the degree of cockle development in paper. In a recent study [Ahrens, et al., 2003], a simple hot-surface dryer (with single-sided heating of the sheet) was employed to quantify the effect on cockle of certain drying-related variables. It was shown that the amount of cockle in the final sheets would be dependent on the proportion of drying occurring under restraint in the dryer (vs. post-dryer unrestrained air drying), as well as on the drying conditions and heat transfer uniformity. None of the cited cockle studies have attempted to simulate the alternating periods of restraint and non-restraint that the sheet experiences as it travels through the typical multi-cylinder dryer section. The WADS would be a reasonable platform for simulating this aspect of the drying process with respect to its influence on cockle development.

\section{THE WEB ADHESION AND DRYING SIMULATOR (WADS)}

The WADS system, shown in Figure 1, consists of a belt driven flywheel to which a removable "coupon" is attached. Coupons $(7.62 \mathrm{~cm} \mathrm{x} 31.30$ $\mathrm{cm}$ ), which represent the dryer cylinder surface, can be made of various materials including cast-iron, steel and chrome-plated steel and can be pre-coated with various model surface contaminants before installation on the WADS system for peel testing. 


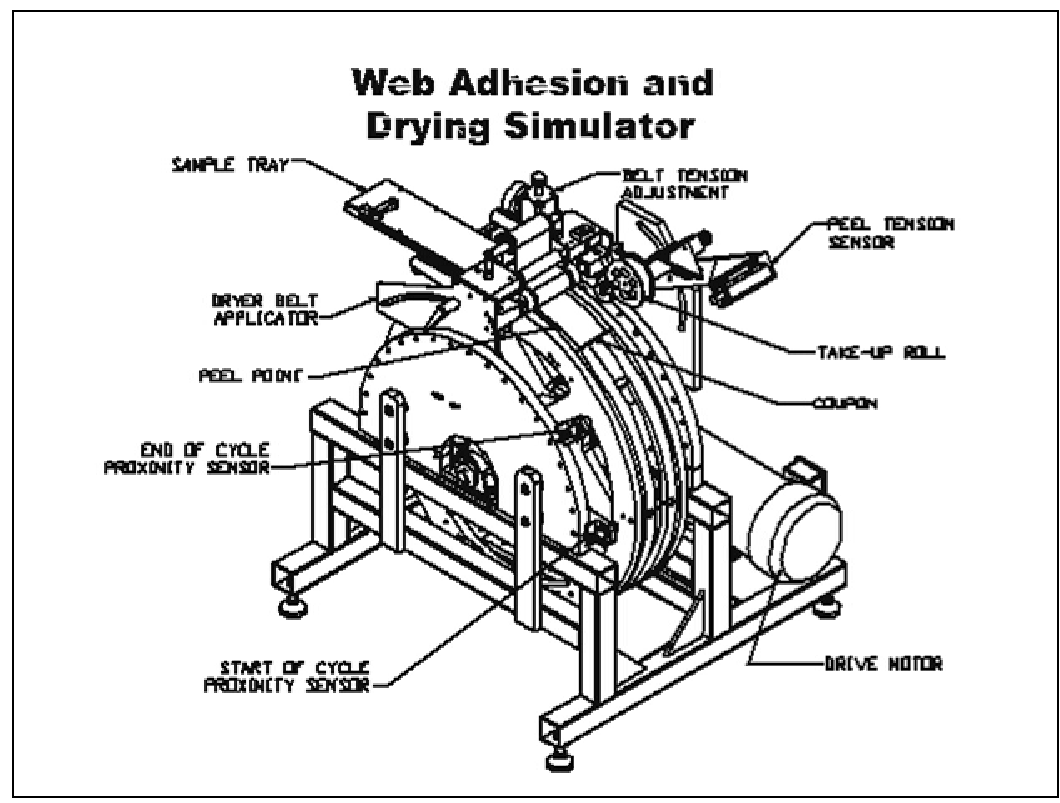

Figure 1: WADS Unit Schematic.

During an experiment, the coupon makes one revolution from its start position at a set peel speed. The dryer belt acts to laminate the web (pulled in from the sample tray) onto the coupon as it rotates past the sample tray. The speed of the wheel and paper contact length of this dryer belt, both user specified parameters, determine the dwell time. After passing through the applicator section, the paper is pulled from the coupon at the specified peel angle and peel point with a length of inelastic fiberglass tape that is tracked over the tension sensor. The sensor records the peel force (tension) required to separate the paper web from the coupon. Note that the measured peel force includes not only the force required to overcome adhesion at the peel point, but also forces resulting from changes in web potential and kinetic energy that occur between the peel point and tension sensor. Upon completion of the peel event, a proximity sensor triggers a brake to stop the wheel.

The WADS has the ability to control and vary several parameters important in simulating realistic drying conditions. The coupon surface temperature can be varied from ambient to $177{ }^{\circ} \mathrm{C}$. Peel angles (sheet take-off angles) can be adjusted from 0 to 90 degrees and a range of peel velocities, from $6 \mathrm{~m} / \mathrm{min}$ to approximately $122 \mathrm{~m} / \mathrm{min}$ is available. Dwell time (contact time between the paper and coupon) is adjustable using a combination of the flywheel rotational speed and dryer belt wrap length, and can be varied from $0.05 \mathrm{sec}$ to approximately $5 \mathrm{sec}$. The typical dwell time of the sheet on a dryer cylinder in a commercial paper machine is on the order of a few tenths of a second, depending on speed, etc. Web application pressure is controlled by belt tension and can be increased up to about $20 \mathrm{kPa}$. The ingoing paper sample temperature, which plays a role in the degree of sticking, can also be adjusted in a range of $20{ }^{\circ} \mathrm{C}$ to $93{ }^{\circ} \mathrm{C}$.

Chemical analysis of dryer cylinder contamination from various mills has revealed the presence of compounds common to adhesives, coatings and binders such as PVAC, polyacrylates and styrene-butadiene latexes. The presence or absence of such compounds on the dryer surface would be expected to influence the picking and adhesion phenomena, but we have found no quantitative published work discussing this issue. We have selected three polymeric materials: a PVAC-based adhesive (Vinac 884 from Air Products), a polyacrylate-based adhesive (Carbotac 16171 from BF Goodrich) and a latex compound (SBR), to model the typical polymer contaminants. Contaminated coupons are prepared by coating the appropriate compound with a gauged metering rod to ensure uniform thickness.

For WADS experiments, paper samples are formed using a Formette Dynamique sheet forming apparatus. Virgin kraft linerboard (VKLB) at 100 $\mathrm{g} / \mathrm{m}^{2}$ and 500-550 CSF was used in the picking/adhesion experiments to be described later. The formed sheets are initially pressed to approximately $35 \%$ solids with a laboratory roll press apparatus. The sheets are cut into $6.35 \mathrm{~cm} \mathrm{x}$ $27.9 \mathrm{~cm}$ sections and joined with a pull tape and Mylar joint to create a WADS paper sample. 
Immediately prior to testing, the sample is dried to the correct moisture content with restrained drying under blotter paper. Video images taken during the equipment debugging stage showed that the actual peel angle can vary significantly from the set point angle for some conditions. This is primarily due to the fact that, at lower levels of adhesion and tension, the paper does not peel from the coupon surface at a sharp angle. Rather, there can be some sheet curvature, due to the effects of the paper sample weight and stiffness. Since the peel angle is required in the Mardon Equation to solve for work of adhesion, an accurate angle measurement is critical. A high-speed digital camera (Olympus PCI-2000S) was thus incorporated into the WADS setup in order to accurately measure peel angles. A frame-byframe image analysis using Optimas, an image analysis software program, is employed to measure peel angle vs. time, for correlation with the tension vs. time measurements. In principle, the "Mardon equation" could then be applied repeatedly, for each discrete time point. However, it should be noted that, if the sheet has curvature, the tension measured at the tension sensor would be different from the tension at the peel point. The two tensions are only equal when the sheet/tape defines a straight line between the peel point and the tension sensor. To correctly account for the actual situation, a modified version of the Mardon equation had to be developed [Ahrens, et al., 2004]. This version is appreciably more complex than the original Mardon equation given above, and will not be repeated here. Example tension and work vs. time data from a peel event are also contained in [Ahrens, et al., 2004]. To provide picking data, a high-resolution digital photo of a set area of the coupon surface is taken following each run. A quantitative measure of the picking is determined using image analysis of the photos to obtain a percentage of the area covered by fibers.

\section{PICKING AND WEB TRANSFER ISSUES}

Some WADS picking and adhesion experiments have been performed with contaminated cast iron coupons. In these tests, the conditions listed in Table 1 were examined. The work and picking results from these tests are summarized in Figure 2.

\section{Table 1: WADS Contaminant Testing Conditions}

\begin{tabular}{|l|l|l|l|}
\hline \multicolumn{1}{|c|}{ Parameter } & \multicolumn{1}{|c|}{ Setting } & \multicolumn{1}{c|}{ Parameter } & \multicolumn{1}{c|}{ Setting } \\
\hline Coupon Surface Temperature & $65{ }^{\circ} \mathrm{C}, 90^{\circ} \mathrm{C}, 150{ }^{\circ} \mathrm{C}$ & Peel Speed & $0.40 \mathrm{~m} / \mathrm{s}$ \\
Dwell Time & $0.194 \mathrm{~s}$ & Set Point Peel Angle & 15 degrees \\
Initial Sheet Temperature & $38{ }^{\circ} \mathrm{C}$ & Paper Type & Liner Board \\
Initial Sheet Solids & $40 \%, 50 \%$ & Contaminants & Carbotac 26171 (B.F. Goodrich) \\
& & & Vinac XX-311 (Air Products) \\
\hline
\end{tabular}

The work results in Figure 2 show somewhat similar trends for the two contaminants. The differences are likely related to differences in the "tackiness" vs. temperature relation for the two materials. For the Vinac case at all temperatures and the Carbotac case at intermediate and high temperature, the work of separation decreases with increasing solids. The Carbotac low temperature, low solids condition $\left(65^{\circ} \mathrm{C}, 40 \%\right.$ Solids $)$ does not fit this trend. It is believed that the water in the sheet at this condition actually reduces the effective tackiness of the surface. This would result in less sticking and consequently lower work of adhesion.

Picking is seen (Figure 2) to decrease at higher solids, regardless of temperature. As the sheet dries, there is stronger sheet cohesion, which consequently inhibits adhesion of fibers to the surface of the coupon. Peak picking values occurred at the intermediate temperature and low solids level, which is consistent with the findings of Meinecke, et al. [1988] and with the "conventional wisdom" of papermakers, who often report that they have to operate at lower temperatures due to the heavy picking encountered at intermediate temperatures.

Some additional interpretation of the picking data in Figure 2 is as follows. At the highest temperature, there is high sheet cohesion and a large degree of fiber bonding as the sheet dries. The sheet cohesion likely dominates over its adhesion to the roll. At the low temperature, the sheet tends to remain wet, so surface tension (physical cohesion) may be holding the sheet together. Although it would be reasonable to assume that the adhesion to the roll may dominate, the interaction of water with the contaminants presents a complication. Because the sheet is at its "wettest" (high solids and low surface temperature), the effective tackiness is greatly reduced as the water 
on the surface of the sheet contacts the hydrophobic coupon surface. The water may actually act to repel the sheet from the surface, resulting in low adhesion and picking. At the intermediate condition, a combination of the two phenomena occurs - weak physical bonds, easily overcome by the adhesion to the roll, are present; but there is also strong local bonding among fibers as the sheet dries. The fibers then come off in clumps, with some fibers adhering to the surface and pulling off others to which they are already bonded. The intermediate temperature condition could exhibit higher picking values than the other two. Evidence for this concept is clearly visible in the photos in Figure 3.
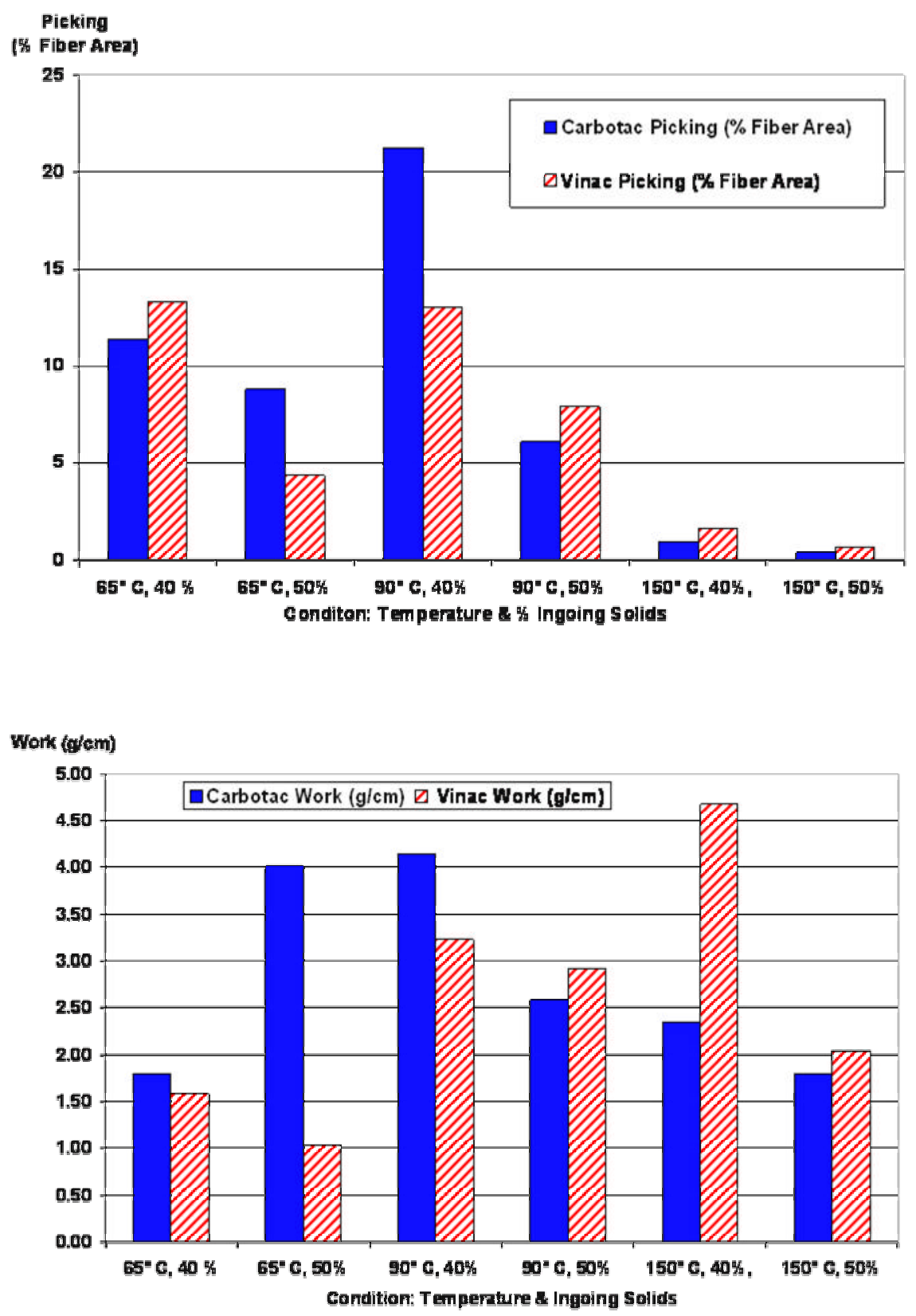

Figure 2: Contamination Summary: Work of Separation and Picking 


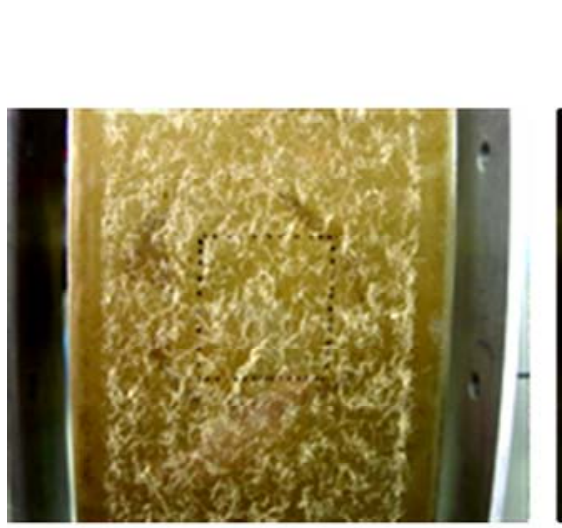

65 0C. $40 \%$

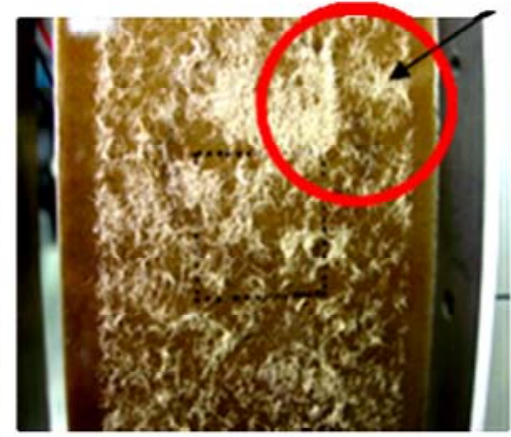

90 0C. $40 \%$
Clumps of Fibers

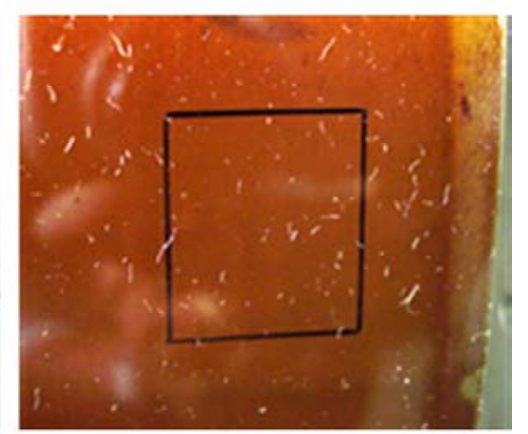

150 0C. $40 \%$

Figure 3: Picking for Contaminated Coupons

It should be noted that, while the trends in the work and picking data have some similarities, they do not appear to have a direct relationship. For example, picking is significantly lower at the highest temperature than at the lowest while work of adhesion values for the two temperatures are similar. Clearly, the relationship among adhesion, cohesion and picking is very complicated. Picking, in particular, is a function of both adhesion and cohesion. A better understanding of cohesion of the sheet at these conditions would help significantly and is one of the major goals for the continuation of this work.

\section{PAPER QUALITY ISSUES: COCKLE DEVELOPMENT}

The WADS has also been utilized to provide a laboratory simulation of the multi-cylinder paper dryer section, to determine the influence of drying conditions on cockle. Test sheets were passed through the WADS multiple times, with alternatesided heating, until a typical final solids level ( 95\%) was reached. Although the test sheet was restrained, by means of a dryer fabric, during each contact with the "dryer cylinder," it was unrestrained between contacts in order to simulate conditions in the open draws. It is primarily in the open draws that evaporation and shrinkage occur.

Two curved, cast iron coupons were employed. One was used bare, to simulate a clean dryer cylinder (uniform heat flux); one was coated with a "checkerboard" pattern of Vinac, to simulate a nonuniformly contaminated dryer cylinder (non-uniform heat flux). Simulated copy paper test sheets were prepared in a Formette Dynamique sheet former to a target basis weight of $70 \mathrm{~g} / \mathrm{m}^{2}$ using a $75 \%$ bleached hardwood kraft/25\% bleached softwood kraft pulp blend. The pulp freeness was approximately $450 \mathrm{CSF}$. The samples were pressed to the desired solids level.

Three test variables were investigated, each at two levels: Dryer surface temperature: $100{ }^{\circ} \mathrm{C}, 157$ ${ }^{\circ} \mathrm{C}$; Surface condition: Bare metal vs. non-uniformly coated surface; and Initial sheet solids level: 40\%, $60 \%$. For each combination of temperature and surface condition, the WADS was used to generate a drying curve. The drying curve is a graph of outgoing solids (starting with sheets at $40 \%$ initial solids) vs. number of heat pulses (simulated dryer cylinders) applied. The applied pressure was $\sim 3.45$ $\mathrm{kPa}$. First, a drying curve for a clean coupon at a surface temperature of $157^{\circ} \mathrm{C}$ (base case), at a dwell time of $0.16 \mathrm{~s}$ (to simulate contact on one $1.52 \mathrm{~m}$ diameter dryer running at $915 \mathrm{~m} / \mathrm{min}$ ), was generated. The sheet was inverted between passes, so that in each successive pass, the opposite surface of the sample contacted the dryer. The drying curve generated determines the number of heat pulses to be used in drying experiments performed to measure cockle. For the base case, 11 passes were needed to reach $95 \%$ solids. Sets of drying curves for other coupon conditions were generated. For these, the dwell time (contact time) per pulse was adjusted by an amount depending on temperature and surface condition, so that the number of pulses (dryer cylinders) needed to achieve $\sim 95 \%$ final solids remained constant. This simulates a fixed paper machine, in which the speed (dwell time) is varied, depending on temperature or degree of contamination, in order to reach a given solids level at the reel. Shown in Table 2 are the adjusted dwell times for each test condition. As expected, the other cases required longer dwell times than the base case, since they all had lower heat transfer rates. 
Table 2: Adjusted Dwell Times

\begin{tabular}{|c|c|c|c|c|}
\hline Condition & Uniform, $\mathbf{1 5 7}{ }^{\circ} \mathbf{C}$ & Non-uniform, $\mathbf{1 5 7}^{\circ} \mathbf{C}$ & Uniform, $\mathbf{1 0 0}{ }^{\circ} \mathbf{C}$ & Non-uniform, $\mathbf{1 0 0}{ }^{\circ} \mathbf{C}$ \\
\hline Dwell (s) & 0.160 & 0.387 & 0.464 & 0.844 \\
\hline
\end{tabular}

For the cockle experiments, samples were dried using alternate-sided heat pulse inputs. For the $60 \%$ initial solids case, the sheets were dried for the number of pulses (seven) needed to dry from $60 \%$ solids to $\sim 95 \%$ as determined by the drying curve, using the same dwell times as were used in the corresponding cases with $40 \%$ initial solids. Four sheet samples were dried for each test condition. Immediately after each test, the sample was placed in a plastic bag. Shortly after the drying experiments, the samples were taken to a 50\% RH conditioned room and the surface topography of each sample was measured using the Shadow Moiré method. A description of the Shadow Moiré method, and its application to the analysis of sheet surface topography, is given in Hojjatie and Coffin [2002]. Each sample was placed and fixed under the glass plate of the Shadow Moire system. Two regions, each with dimensions of $3.8 \mathrm{~cm} \times 4.45 \mathrm{~cm}$ were selected on each sample and an image of each region was captured using a 20 line-per-cm grating. These topography images contained both lower frequency values (curl) and higher frequency values (cockle). In order to separate cockle data from the combined out-of-plane deformations of curl and cockle, appropriate filtering techniques were performed. The standard deviation of the surface height from the best-fit plane (following removal of curl) is an appropriate parameter to characterize cockle [Ahrens, et al., 2003]. Examples of cockle in sheets dried from an initial solids level of $40 \%$ under different test conditions are shown in Figure 4. The units used for the in-plane axes on these images are in pixels. The standard deviations of the cockle for these samples were 3.68 mils (a), 5.99 mils (b), and 10.19 mils $(\mathrm{c})$. Note that $1 \mathrm{mil}=0.001$ inch $=$ $0.00254 \mathrm{~cm}$.

Shown in Figure 5 is a comparison of cockle standard deviation (St-Dev, mils) for samples subjected to uniform (control) and non-uniform drying conditions, at drying temperatures of $100{ }^{\circ} \mathrm{C}$ and $157{ }^{\circ} \mathrm{C}$, and in-going solids levels of $40 \%$ and $60 \%$. In general, all non-uniformly dried sheets had greater cockle than the corresponding control (i.e., uniformly dried) sheets. Among the sheets subjected to a non-uniform drying condition, the sheets at an initial solids level of $40 \%$ that dried at a surface temperature of $157^{\circ} \mathrm{C}$ ( $\mathrm{LH}$ case in Figure 5) had a significantly greater cockle than other sheets. The standard deviation of cockle was smallest for the samples dried uniformly at a $60 \%$ in-going solids and $100{ }^{\circ} \mathrm{C}$ dryer surface temperature. Dryer temperature had a negligible effect on cockle for the condition of $40 \%$ in-going solids/uniform dryer surface. For other cases, the cockle parameter (St_Dev) increased with an increase in surface temperature (drying rate). The influence of surface temperature in cockle was more significant for the condition of $40 \%$ in-going solids and non-uniformly contaminated dryer surface.
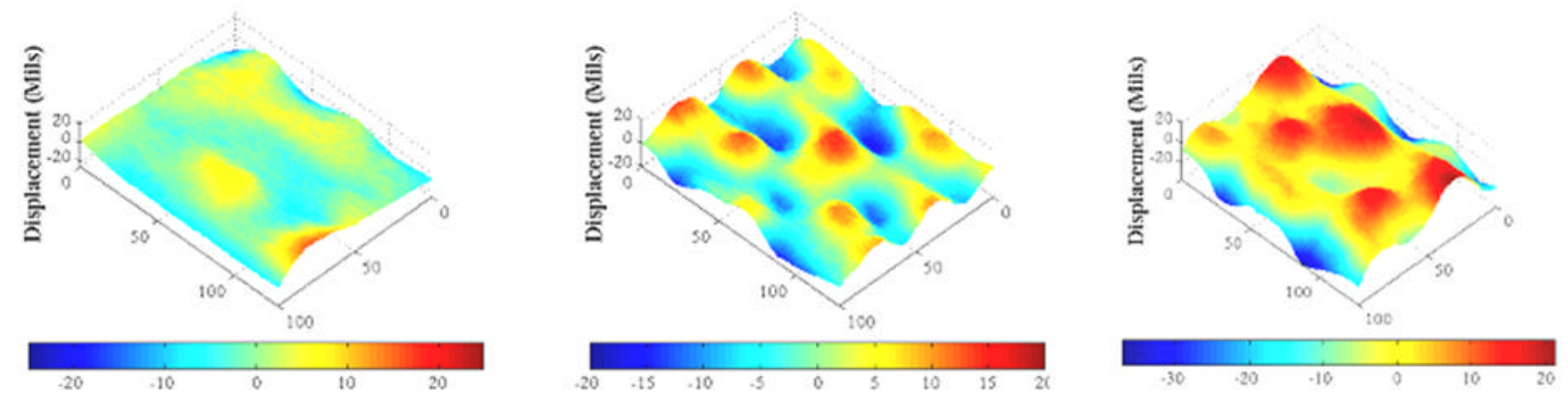

Figure 4: Examples of cockle sheet for samples at an initial solids of $40 \%$ subjected to uniform drying at $157^{\circ} \mathrm{C}$ (a), non-uniform drying at $100{ }^{\circ} \mathrm{C}(\mathrm{b})$, and non-uniform drying at $157{ }^{\circ} \mathrm{C}$ (c). 
St. Deviation (mil s)

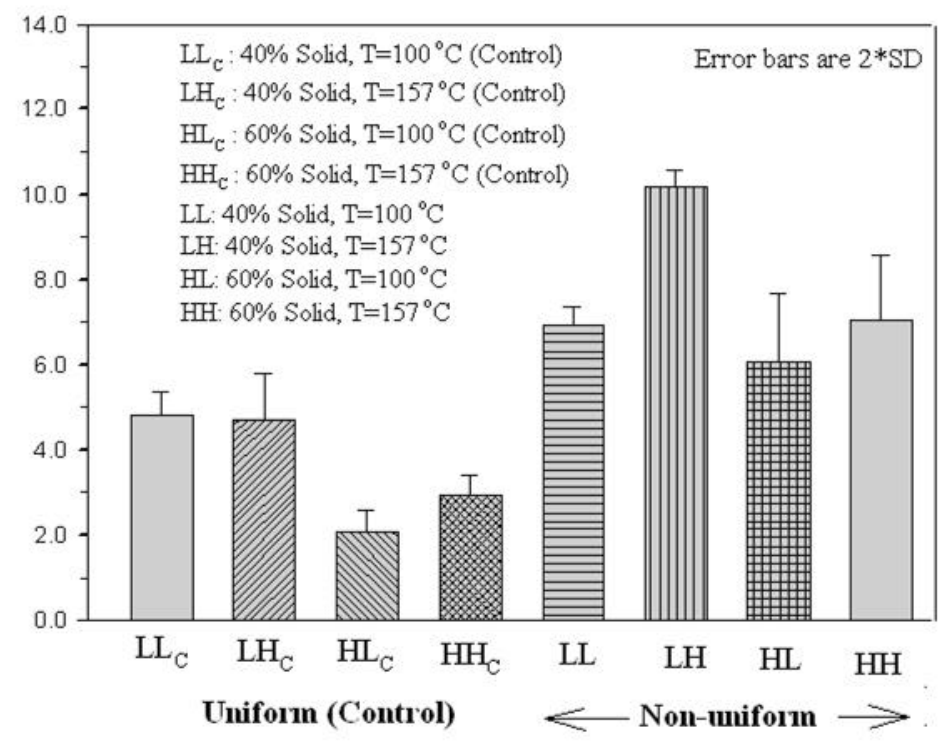

\section{Drying Condition}

Figure 5: Cockle standard deviation results.

\section{CONCLUDING REMARKS}

The WADS is an effective tool for evaluating the adhesion and picking associated with peeling of paper web samples from simulated dryer cylinder surfaces. The results confirm that surface temperature and sheet solids level influence both the work of separation and the picking. Interpretation of results would be aided certain fundamental mechanistic relationships. It would be desirable to have descriptions of the viscoelastic stress-strain and cohesion behavior of paper webs under relevant moisture, temperature and consolidation conditions. It would also be of interest to measure or predict the local sheet temperature and moisture at the sheet roll surface interface (at the peel point).

The WADS is a suitable device to study cockle; it provides a simplified simulation of the multicylinder drying process. Cockle was greatest for the samples dried non-uniformly at lower solids and higher dryer temperature; it was smallest for samples dried uniformly at a higher solids and lower dryer temperature. Cockle in sheets dried on a nonuniformly contaminated dryer surface was greater than for those dried on a clean surface. In general, comparing with a clean dryer cylinder, the role of drying temperature in development of severe cockle becomes more important when the dryer surface is contaminated.

\section{ACKNOWLEDGEMENTS}

The authors acknowledge support of by the IPST Member Companies and the U.S Department of Energy (Award DE-FC36-99G010384). The expertise of J. Chabot in designing the WADS and the assistance of Melissa Austin in the WADS experiments is greatly appreciated.

\section{NOMENCLATURE}

$\begin{array}{llr}\mathrm{m} & \text { mass per unit area } & \mathrm{kg} / \mathrm{m} 2 \\ \text { T’ } & \text { tension per unit width } & \mathrm{N} / \mathrm{m} \\ \mathrm{V}_{1} & \text { velocity of the sheet } & \mathrm{m} / \mathrm{s} \\ W^{\prime} & \quad \begin{array}{l}\text { work of adhesion (or separation) } \\ \text { per unit area }\end{array} \\ \phi \quad l \text { peel angle (relative to the surface } & (-) \\ \phi & \quad(-)\end{array}$

\section{REFERENCES}

Ahrens, F., Hojjatie, B., Coffin, D. (2003), Influence of Drying Variables in Development of Cockle: an Experimental Study, Proceedings 2003 International Paper Physics Conference (Victoria, B.C.), 137-142. 
Ahrens, F., Mueller, S., Patterson, T., Bloom, F. (2004), Mathematical Modeling of Web Separation and Dynamics on a Web Adhesion and Drying Simulator, to appear in Int. J. Applied Mechanics and Engineering, 9(3).

Brecht, W., Müller, F., Weiss, H. (1955), Über das 'Blasigwerden' von Papieren, Das Papier, 9(7/8), pp. 133-142.

Hojjatie, B., Coffin, D.W. (2002), Measurement and Analysis of Sheet Topography using Shadow Moiré System" Proceeding of Progress in Paper Physics, Finger Lakes, New York, pp. 168-171.

Mardon, J. (1961), The Release of Wet Paper Webs from Various 'Papermaking Surfaces', APPITA, 15(1), pp.14-34.

Mardon, J. (1976), Theoretical and experimental investigations into the peeling of paper webs from solid surfaces, Paperi ja Puu, No. 11, pp.797-815.

Meinecke, A., Chau Huu, T., Loser, H. (1988), Neue Erkenntnisse über die Papiertrocknung mit Trockenzylindern, Das Papier, 42(10A), pp.159-165.

Shallhorn, P. M., Karnis, A. (1975), The Mechanism of Picking at the Presses of a Papermachine, Proceedings of the $61^{\text {st }}$ Meeting of the CPPA, CPPA, Montreal, pp. B127-B132.

Smith, S.F. (1950), Dried-In Strains in Paper Sheets and their Relation to Curling, Cockling and Other Phenomena, The Paper-Maker and British Paper Trade Journal, pp. 185-192.

Ueska, T. (1991), Dimensional Stability of Paper: Upgrading Paper Performance in End Use, J. Pulp Paper Science, 17(2), pp. J39-J46. 